Tetrahedron Letters No. 37, pp 3245 - 3248, 1976. Pergamon Press. Printed in Great Britain.

\author{
A DIRECT SYNTHETIC APPROACH TO FUNCTIONALIZED \\ DIVINYLCYCLOPROPANES AND CYCLOHEPTADIENES. \\ J. P. Marino* and L. J. Browne \\ Department of Chemistry, University of Michigan, \\ Ann Arbor, Michigan 48109
}

(Received in USA 28 May 1976; received in UK for publication. 26 Jaly 1976)

We have recently described a novel and general synthetic approach to ring fused cycloheptadienes via functionalized divinylcyclopropanes. 1 In this approach, the divinylcyclopropane system was constructed by a two-step sequence involving a carbonyl-stabilized vinylsulfoxonium methylide and a Wittig reaction. The methodology utilized the combination of two three-carbon units and a one-carbon wittig reagent to comprise the seven carbons of the ultimate cycloheptadiene (Scheme A).

\title{
Scheme A
}
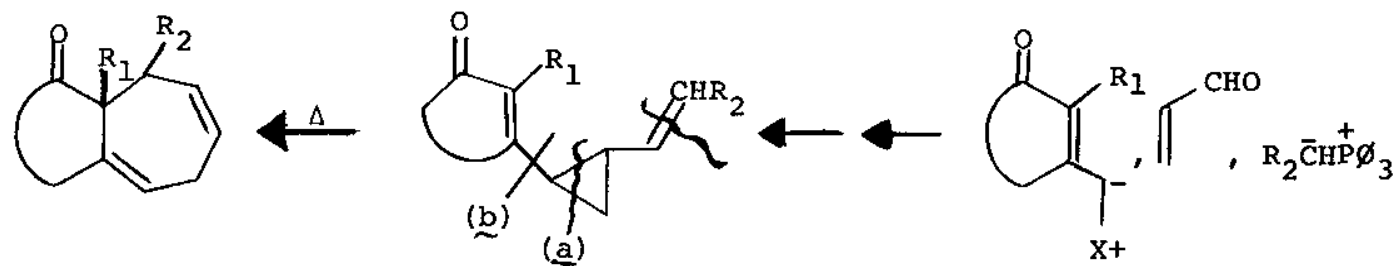

In this report we plan to describe alternative methodology for the construction of functionalized divinylcyclopropanes and hence, cycloheptadienes which is based on the regiospecific formation of an enone-cyclopropane bond ${ }^{2}$ (indicated above by the solid line $\underset{\sim}{b})$. We believe that this approach offers greater flexibility in substitution patterns and complements our ylide approach. Some of the required metallocyclopropanes needed to affect this synthetic approach are described in our accompanying paper. ${ }^{3}$ we shall concentrate here on the several variations possible for the utilization of vinylcyclopropyllithium and copper reagents. 
1,2-Additions of 2-Vinylcyclopropyllithium Derivatives. The availability of substituted vinylcyclopropyllithium reagents suggests a direct approach to cycloalkenone substituted vinylcyclopropanes which involves a facile transposition of 1,3-dicarbonyl functionality. Thus, the lithio reagents $1-3$ added cleanly to $\beta$-ethoxycyclohexenone and 2-methy1-3-methoxycyclopentenone at $-78^{\circ} \mathrm{C}$ in THF/Et ${ }_{2} O$ to initially produce the allylic alcohols. Upon work-up of the reactions with an aqueous ammonium chloride solution, the divinylcyclopropane systems $4-6$ were produced. ${ }^{5}$ The reactions of $\frac{1-3}{5}$ with the enol ether of 2-methyl-1,3-cycloheptanedione are summarized below.
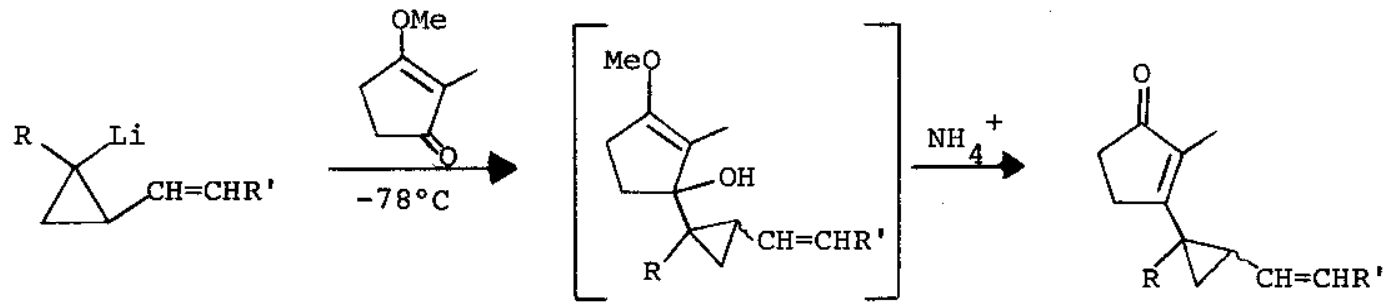

$$
\begin{array}{ll}
\frac{1}{2} & \begin{array}{l}
\mathrm{R}=\mathrm{R}^{\prime}=\mathrm{H} \\
\mathrm{3}
\end{array} \\
\mathrm{R}=\mathrm{H}, & \mathrm{R}^{\prime}=\mathrm{SPh} \\
\mathrm{R}=\mathrm{Me}, & \mathrm{R}^{\prime}=\mathrm{H}
\end{array}
$$

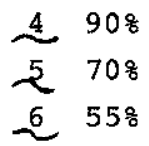

Compounds 4 and 5 were thermally rearranged to the corresponding hydroazulene systems as previously described. ${ }^{1}$ compound 6 , derived from the more hindered $t$-cyclopropyl reagent, was formed in lowest yield, and was a 2:1 mixture of the $\mathrm{E} / \mathrm{Z}$ stereoisomers. ${ }^{6}$ The $\mathrm{Z}$ isomer rearranged as expected at about $100^{\circ} \mathrm{C}$ to yield the hydroazulene derivative 7 containing a key methyl substituent. Not surprising, thermal rearrangement of the $\frac{E}{\mathrm{E}}$ isomer led to the product (8) which resulted from a homo $[1,5]$ sigmatropic shift. 7

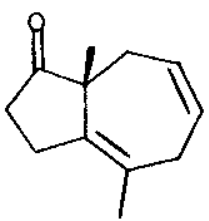

$\stackrel{7}{2}$

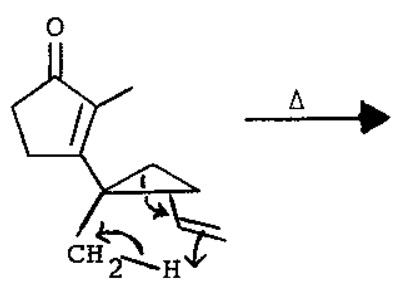

The alternative approach to compounds 4-6 via conjugate additions of the copper reagents of $1-3$ to $\beta$-halo or $\beta$-acetoxycycloalkenones was considered to offer no real advantages over the 1,2-additions. The use of copper reagents involves the formation of an additional reagent and the $\beta$-halosubstrates are derived from the same 1,3-diones as the enol ethers used above. 
1,4-Additions to $\alpha, \beta$-Acetylenic Carbonyl Compounds. One of the most useful reactions of the 2-vinylcyclopropyl copper reagents, described in the accompanying paper, is the conjugate addition of these reagents to acetylenic ketones and esters. This approach offers additional options for constructing functionalized cycloheptadienes. When the homocuprate 9 , prepared ${ }^{3}$ from 1 , was treated with methyl propiolate at $-78^{\circ} \mathrm{C}$, the trans-divinylcyclopropane 10 (80\%) and the rearranged cycloheptadiene 11 (15\%) were both isolated. 8 subsequent rearrangement of 10 at $140^{\circ} \mathrm{C}$ yielded 11 quantitatively. The copper reagents 2 and 12 were also added to the acetylenic ketone 13 in greater than $90 \%$ yield. In both cases, an 8:1 mixture of the trans-divinylcyclopropanes 14 and the corresponding cycloheptadienes 15 was produced.
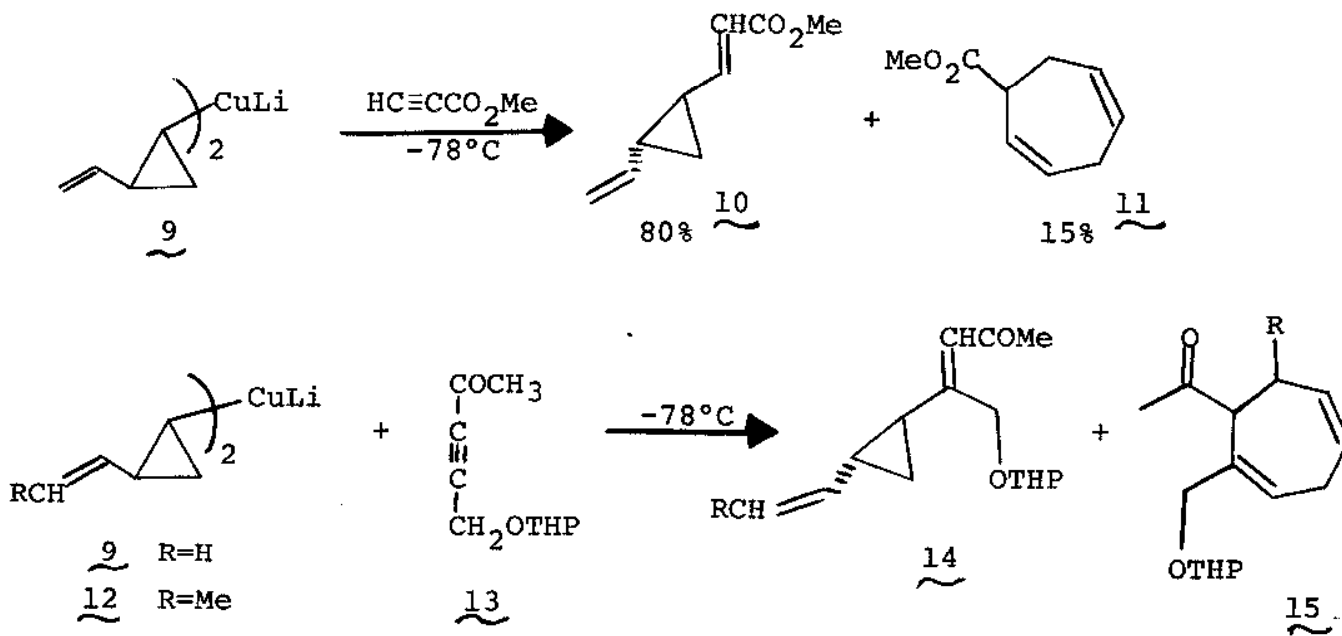

The generation of cycloheptadienes such as 15 also provides for another approach to hydroazulenes via closure of the cyclopentenone ring. Work is currently underway in our laboratories to utilize this synthetic strategy.

As a final variation in the sequence for constructing the divinylcyclopropane system, we have added the cuprate reagent ${ }^{3}$ derived from the 2-Iithiocyclopropane carbaldehyde diethyl acetal to the acetylenic ketone 13 . The combined yield of the $\mathrm{E}$ and $\mathrm{Z}$ isomers $(\mathrm{E} / \mathrm{Z}=2 / 1)$ was $81 \%$.

The selected examples of the vinylcyclopropyl organometallics outlined above illustrate a number of ways one may set up a functionalized divinylcyclopropane system for subsequent rearrangement to a cycloheptadiene derivative. Further improvements in the experimental conditions for the various metallations may provide for the stereospecific construction of the cisdivinyl isomer and thus avoid complications such as was encountered in the formation of 8 . 
Acknowledgment is made to the donors of the Petroleum Research Fund, administered by the American Chemical Society, for partial support of this research. L.J.B. also gratefully acknowledges the Department of Chemistry's Samuel H. Baer Scholarship Fund for fellowship support.

\section{References and Footnotes}

1. J. P. Marino and T. Kaneko, Tetrahedron Lett., 3971 and 3975 (1973); (b) J. Org. Chem.; 39, 3175 (1974).

2. Related work in our laboratories on the conjugate additions of lithium dicyclopropylcuprate to $\alpha, \beta$-unsaturated carbonyl compounds has been sub-

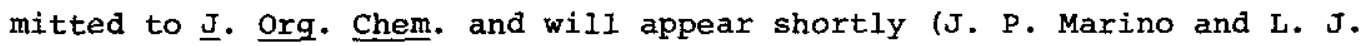
Browne).

3. J. P. Marino and L. J. Browne, Tetrahedron Lett., 0000 (1976).

4. The reaction of reagent 1 with this substrate produced only the transdivinylcyclopropane ( $80 \%$ ) after work-up with ammonium chloride.

5. Compounds 4 and 5 and their rearrangement products have been previously described in reference $1 b$. A11 new compounds have given satisfactory elemental analysis and possessed spectral (NMR, IR and MS) data consistent with the assigned structures.

6. The yields indicated represent total isolated material which was composed of the cis- and trans-divinylcyclopropane isomers and in some cases the hydroazulene skeleton resulting from rearrangement of the cis-isomer. [4, 828 trans, 88 rearranged cis; 5, $\sim 4: 1$ mixture of E:z cyclopropanes.]

7. R. B. Woodward and R. Hoffmann, The Conservation of orbital Symmetry, Academic Press, New York, 1970, p. 132 and references therein.

8. The cuprate reactions were carried out under an Argon atmosphere at $-78^{\circ} \mathrm{C}$ in a solvent mixture of THF and ether $(\sim 2: 1)$ for approximately one hour.

9. The ketone 13 was prepared by the reaction of the cuprous acetylide of propargyl alcohol-THP ether and acetyl chloride. 